\title{
Spinal Cord Epidurial Stimutation for Neuropathic Pain Syndrome Treatment of Disseminated Sclerosis patient
}

DOI: $10.17691 /$ stm2015,7.2.24

Received February 13, 2015

I.N. Morozov, MD, DSc, Senior Researcher, Consultation and Rehabilitation Department;

A.1. Ushakov, Researcher, Department of the Neurosurgical

Privolzhsky Federal Research Medical Center, Ministry of Health of the Russian Federation, 18 Verkhne-Votzhskaya naberezhnaya St., Nizhny Novgorod, 603155, Russian Federation

The paper describes successful treatment case of medicamentally-resitant chronic neuropathic pain syndrome of 63 year old patient with cerebro-spinal form of disseminated sclerosis. For the purpose of pain correction the patient received percutaneous implantation of epidural electrodes and Medtronic pulse generator (USA) which allowed for pain reduction by $50 \%$, refusal of semi-narcotic analgesics taking and revert to habitual everyday activity.

Key words: neuropathic pain; neuromodulation; disseminated sclerosis.

Neuromodulation forms an integral part of chronic exhausting pain management algorithm. There are clinical evidences of its efficiency for postoperative back bone disease $[1,2]$ and complex regional pain syndrome [3-5]. A number of researchers supports spinal cord stimulation for peripheral neuropathy, ischemic pain, peripheral vascular diseases and stenocardia [6-8]. Peripheral nerve stimulation has a beneficial effect for neuralgia of occipital, supraorbital, ilioinguinal and intercostal nerves [9-12]. There is information about neurostimulation application in visceral pain therapy [13-15].

Although there are no domestic publications concerning use of functional neurosurgery in neuropathic pain syndrome therapy for disseminated sclerosis patients and there are few foreign publications of the type, the authors decided to use neurostimulation procedure for treatment of severe chronic neuropathic pain syndrome of a disseminated sclerosis patient. In case of test stimulation positive effect they planned to carry out hypodermic implantation of pulse generator to perform chronic neuromodulation.

Hereby we provide an example of such a patient successful treatment.

Patient T., 63 years old, was admitted to Neurosurgery Department of the Nizhny Novgorod Research Institute of Traumatology and Orthopedics on 28.10.2013, diagnosed with: "disseminated sclerosis, cerebro-spinal form, myeloradiculopathy. Chronic neuropathic pain syndrome". At admission the patient presented problems with severe pains in the left hemithorax and left side of abdominal region.

Past medical history: for 10 years has been followed in the Disseminated Sclerosis Center (Nizhny Novgorod) with regard to the diagnosis: "disseminated sclerosis, cerebrospinal form". 6 years ago persistent pains developed in the left side of abdominal region and left hemithorax. For 5 years the pain syndrome has augmented, the patient took Tramal (tramadolum) up to $400 \mathrm{mg}$ per day, Lyrica (pregabalin) up to $600 \mathrm{mg}$ per day. At the moment of examination the pain score according to the visual analogue scale (VAS) was up to 8 points, according to pain questionnaire testing DN4 [16] - 5 point which furnished convincing proof of pain syndrome neuropathic nature. Self-care and mobility of the patient were disturbed partially: moving in bed (20 of 25 points), dressing (24 of 40 points), personal hygiene activities (30 of 35 points) according to the functional estimation scale for activity and quality of life - VFM [17].

Physical examination data: consciousness - clear, speech - correct, oriented. On the side of cranial nerves no asymmetry. Active movements in upper and lower limb joints - to the full extent. Muscle strength of upper limbs is not changed; muscle strength of lower limbs is decreased to 4 points. Limb tendon reflexes are evenly impaired. Muscle tone in upper and lower limbs is slightly up (2 points by Ashworth scale).

In thoracolumbar region of vertebral column, a Cshaped antalgic scoliotic deformation, tension of thoracic paravertebral back muscles, hypoesthesia with hyperpathia elements along 9, 10, 11 intercostal nerve on the left are noted. Movements in lumbar column are limited to $50 \%$ of usual norm. Moves supported by "Canadian" stick.

After comprehensive approach to the patient (CT, MRT, biochemical and clinical analyses, specialists' examination) surgical and oncologic pathology is excluded, the patient is recommended neuromodulation. Patient informed consent for use of data was obtained.

Under regional anesthesia (30 $\mathrm{ml}$ of $1 \%$ lidocain) made a $5 \mathrm{~cm}$ cut in vertebra $L_{\text {III }}$ projection. Using Tuohy

For contacts: Morozov Ivan Nicolaevich, ivanmorozov@list.ru 
needle, to the left of center line performed a puncture of the back epidural cavity. Under guidance of a special $X$ ray apparatus - $C$-arc - epidurally installed a cylindrical electrode Medtronic (USA) which four terminals were located in the area of vertebra $T h_{X}-T h_{\text {VIII }}$ above respective segment of the spinal cord (Figure 1). Then, using a connection cable the electrode was terminated at the test stimulation apparatus (Figure 2). As is customary, during test stimulation it is necessary to achieve paresthesia which would fully correspond to pain zone localization and excite no unpleasant sensations. However, in case with patient $T$. impaired awareness did not allow to get the expected paresthesia. The procedure efficiency was judged by considerable abatement of pain sense in respective dermatomes. The right effect was achieved in the course of test electrical stimulation already on the operation table at current amplitude from $1.5 \mathrm{~W}, 40 \mathrm{~Hz}$ frequency and $240 \mu$ s pulse width. The patient noticed pain abatement by a quantity no less than $50 \%$ of the initial level.

At the first stage the electrode was connected to a temporary connector which was taken out via a counteropening. Test monitoring was carried out for 7 days. Within this period of time the patient was trained in using the system for chronic electrical stimulation, carried out stimulation sessions independently. At the same time they selected the stimulation mode (session daily periodicity, duration of each session), stimulation parameters (amplitude, frequency, pulse width).

Before and after a stimulation session the patient assessed the pain syndrome by standard scales. Since the patient noticed considerable abatement of pain syndrome severity (normally, by $50 \%$ and more of the initial level), they carried out the second stage of the operation, i.e. implantation of subdermic system part. That stage was also performed under regional anesthesia. Electrodes were tunneled in the area of subdermic pocket formed for the pulse generator and connected to the latter.

In result of chronic neuromodulation pulse generator implantation they managed to obtain pain abatement by $50 \%$ (from 8 to 4 points according to VAS), refuse seminarcotic analgesics taking, and revert to habitual everyday activity. Self-care assessment using the functional estimation scale for patients with spinal cord injury VFM over time demonstrated achievement of maximum possible indicators by all items: moving in bed - 25, dressing - 40, personal hygiene activities - 35 points. In a year, the pain intensity never exceeded 3-4 points, the patient periodically takes non-steroidal analgesics, there are no self-care limitations caused by the pain.

Spinal cord epidural stimulation procedure in chronic neuropathic pain therapy under disseminated sclerosis demonstrated good results: they managed to achieve considerable and constant pain recession and as a consequence to restore self-care and habitual everyday activity. Certainly, neuromodulation execution under demyelination has specific features; particularly, they

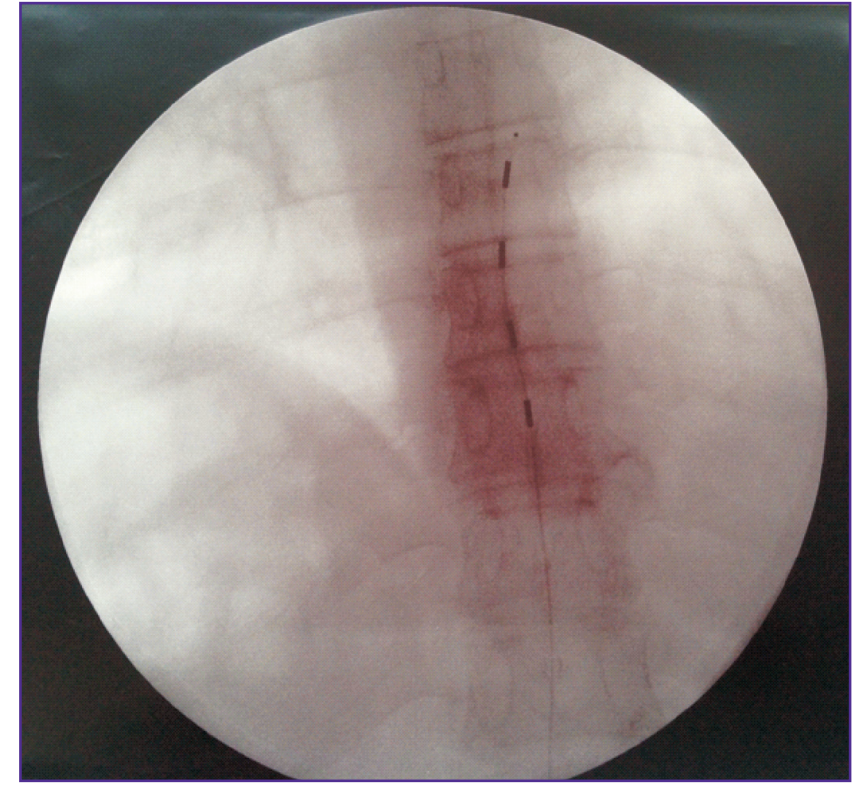

Figure 1. Electrode location in the vertebral canal

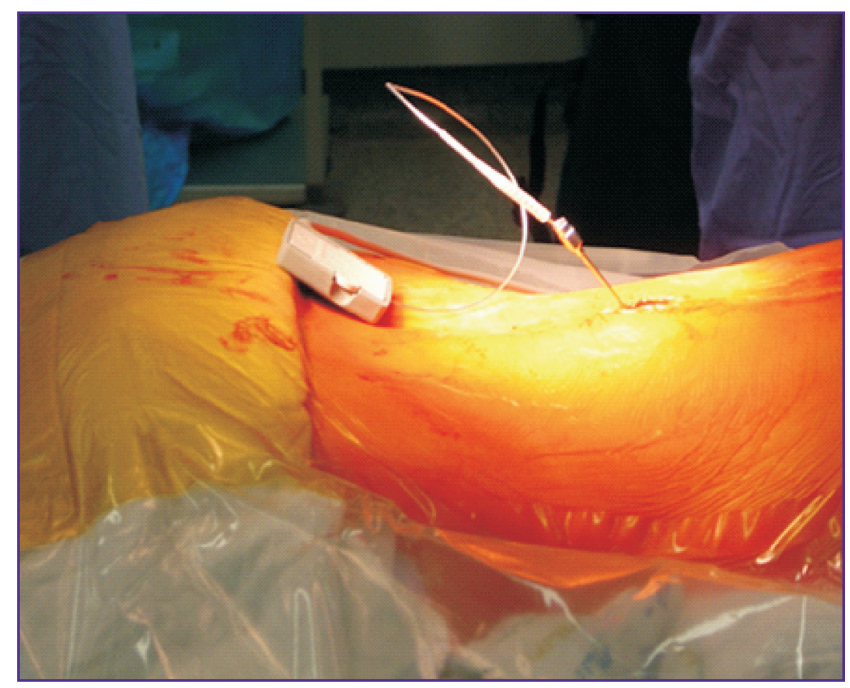

Figure 2. Test stimulation performance

failed to achieve definitive paresthesia in the neuropathic pain zone. However, the technology is promising in terms of targeted action on local pain and absence of systematic action which is hot issue for patients with similar nosology. The method allows for minimally invasive action/effect achievement and it can be successfully used in the algology.

Study Funding. The research has not been financed from any source.

Conflict of Interest. The authors have no conflict of interest.

\section{References}

1. McRoberts W.P., Wu P., Bentley I. Effect of a novel fixation method for spinal cord stimulators. Neuromodulation: 
Technology at the Neural Interface 2013; 16(5): 449-453, http://dx.doi.org/10.1111/j.1525-1403.2012.00499.x.

2. Deer T., Krames E., Hassenbusch S., Burton A., Caraway D., Dupen S., et al. Management of IT catheter-tip inflammatory masses: an updated 2007 consensus statement from an expert panel. Neuromodulation: Technology at the Neural Interface 2008; 11(2): 77-91, http://dx.doi.org/10.1111/ j.1525-1403.2008.00147.x.

3. Bernstein C.A., Paicius R.M., Barkow S.H., LempertCohen C. Spinal cord stimulation in conjunction with peripheral nerve field stimulation for the treatment of low back and leg pain: a case series. Neuromodulation: Technology at the Neural Interface 2008; 11(2): 116-123, http://dx.doi.org/10.1111/ j.1525-1403.2008.00152.x.

4. Oaklander A.L., Rissmiller J.G., Gelman L.B., Zheng L., Chang Y., Gott R. Evidence of focal small-fiber axonal degeneration in complex regional pain syndrome-I (reflex sympathetic dystrophy). Pain 2006; 120(3): 235-243, http:// dx.doi.org/10.1016/j.pain.2005.09.036.

5. Perez R.S., Zollinger P.E., Dijkstra P.U., ThomassenHilgersom I.L., Zuurmond W.W., Rosenbrand K.C.J., et al. Evidence based guidelines for complex regional pain syndrom type 1. BMC Neurol 2010; 10(1): 20, http://dx.doi. org/10.1186/1471-2377-10-20.

6. Daousi C., Benbow S.J., MacFarlane I.A. Electrical spinal cord stimulation in the long-term treatment of chronic painful diabetic neuropathy. Diabet Med 2005; 22(4): 393-398, http://dx.doi.org/10.1111/j.1464-5491.2004.01410.x.

7. Deer T.R., Raso L.J. Spinal cord stimulation for refractory angina pectoris and peripheral vascular disease. Pain Physician 2006; 9: 347-352.

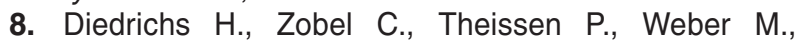
Koulousakis A., Schicha H., Schwinger R.H. Symptomatic relief precedes improvement of myocardial blood flow in patients under spinal cord stimulation. Curr Control Trials Cardiovasc Med 2005; 6(1): 7, http://dx.doi.org/10.1186/14686708-6-7.
9. Weiner R.L. Occipital neurostimulation (ONS) for treatment of intractable headache disorders. Pain Med 2006; 7(s1): S137-S139, http://dx.doi.org/10.1111/j.15264637.2006.00129.x.

10. Slavin K.V., Nersesyan H., Wess C. Peripheral neurostimulation for treatment of intractable occipital neuralgia. Neurosurgery 2006; 58(1): 112-119, http://dx.doi. org/10.1227/01.neu.0000192163.55428.62.

11. Mammis A., Bonsignore C., Mogilner A. Thoracic radiculopathy following spinal cord stimulator placement: case series. Neuromodulation: Technology at the Neural Interface 2013; 16(5): 443-448, http://dx.doi.org/10.1111/ner.12076.

12. Paicius R.M., Bernstein C.A., Lempert-Cohen C. Peripheral nerve field stimulation in chronic abdominal pain. Pain Physician 2006; 9(3): 261-266.

13. Qin C., Lehew R.T., Khan K.A., Wienecke G.M., Foreman R.D. Spinal cord stimulation modulates intraspinal colorectal visceroreceptive transmission in rats. Neurosci Res 2007; 58(1): 58-66, http://dx.doi.org/10.1016/ j.neures.2007.01.014.

14. Krames E.S., Foreman R. Spinal cord stimulation modulates visceral nociception and hyperalgesia via the spinothalamic tracts and the postsynaptic dorsal column pathways: a literature review and hypothesis. Neuromodulation: Technology at the Neural Interface 2007; 10: 224-237, http:// dx.doi.org/10.1111/j.1525-1403.2007.00112.x.

15. Kapural L., Rakic M. Spinal cord stimulation for chronic visceral pain secondary to chronic non-alcoholic pancreatitis: a case report. Clin Gastroenterol Hepatol 2008; 42(6): 750-751, http://dx.doi.org/10.1097/01.mcg.0000225647.77437.45.

16. Bouhassira D., Attal N., Fermanian J., Alchaar H., Gautron M., Masquelier E. Development and validation of the neuropathic pain symptom inventory. Pain 2004; 108(3): 248257, http://dx.doi.org/10.1016/j.pain.2003.12.024.

17. Belova A.N. Shkaly, testy $i$ oprosniki $v$ nevrologii $i$ neyrokhirurgii [Scale tests and questionnaires in neurology and neurosurgery]. Moscow; 2004; $434 \mathrm{p}$. 